\title{
¿SUBSISTEN DISCRIMINACIONES EN EL ACTUAL RÉGIMEN LEGAL CHILENO DE FILIACIÓN?*
}

\author{
HERnÁn CORRAL TALCIANI** \\ Universidad de los Andes
}

\begin{abstract}
RESUMEN: El trabajo discute si el actual régimen jurídico de la filiación en el ordenamiento jurídico chileno respeta o desatiende el principio de igualdad jurídica. Se intenta una distinción entre lo que son diferencias justificadas y no justificadas e igualmente una separación de los problemas de igualdad entre los progenitores en las relaciones para con el hijo, y lo que son discriminaciones entre los hijos. Se defiende que el estándar del interés superior del niño puede justificar diferencias razonables entre los progenitores respecto a su igualdad en cuanto a los derechos y potestadores sobre sus hijos. Se concluye con dos supuestos en los que puede discutirse la subsistencia de discriminaciones arbitrarias entre hijos: la determinación judicial postmortem de la paternidad y la investigación de esta en el caso de técnicas de reproducción asistida con aporte de gametos de terceros.
\end{abstract}

Palabras clave: Filiación, igualdad, discriminación, familia, progenitores.

ABSTRACT: The objective of this essay is to deliberate if the actual Chilean legal regime of parentage respects or disregards the principle of legal equality. The essay attempts to draw a distinction between justified and unjustified differences, and issues of equality in the relationship between parents and the child and discrimination among the children. The author argues that the standard of superior interest for the child may justify reasonable differences among parents regarding the rights and authority over their children. Two scenarios of arbitrary discrimination are concluded, the judicial determination of postmortem paternity and postmortem investigation regarding assisted reproduction techniques with input from third-party gametes.

Key words: Affiliation, equality, discrimination, family, parents.

\section{DISCRIMINACIÓN Y PRINCIPIO DE IGUALDAD JURÍDICA}

El sesgo negativo que suele acompañar actualmente a la palabra discriminación puede conducir a una falencia argumentativa cuando se pregunta sobre las discriminaciones que se generan o subsisten en una determinada regulación legal. En efecto, si se entiende discriminación como toda diferenciación injusta, inicua y reprochable, el juicio ya está adoptado: ella debe desaparecer. Pero discriminar puede ser tomado en un sentido neutro, descriptivo, como sinónimo de seleccionar, de diferenciar, sin evaluar si esa distinción puede ser considerada justa o injusta.

Es importante partir de una concepción uniforme de discriminación para que el diálogo y la discusión sobre ella sea realmente fructífera. Partimos, pues, de la afirmación de que

\footnotetext{
El presente artículo fue publicado en Colección Leyes y Sentencias, No 105, pp. 1-9. Santiago, Chile: Thompson Reuters Puntolex, 2010.

** El autor es Licenciado en Derecho por la Pontificia Universidad Católica de Chile, Doctor en Derecho por la Universidad de Navarra (España), Profesor Titular de Derecho Civil de la Facultad de Derecho Universidad de los Andes.
} 
el principio jurídico de igualdad admite (o incluso exige) las diferencias: discriminaciones en sentido neutro, y solo excluye aquellas que sean injustas.

La jurisprudencia de los tribunales constitucionales y de derechos humanos es pródiga en afirmar que no toda diferencia debe ser considerada injusta o discriminatoria, por contraria al principio de igualdad jurídica, sino que solo aquellas que no tengan una suficiente justificación por la razonabilidad de los elementos relevantes para la diferenciación y la congruencia y proporcionalidad de la finalidad perseguida por la norma.

Como ejemplo podemos tomar una sentencia judicial del Tribunal Constitucional español dictada justamente en un problema de filiación, y en la que se esclarece la forma en la que debe operar la evaluación de si la diferencia legal es o no motivo de reproche según el principio de igualdad jurídica:

“(...) el principio de igualdad 'ante o en la Ley' impone al legislador el deber de dispensar un mismo tratamiento a quienes se encuentran en situaciones jurídicas iguales, con prohibición de toda desigualdad que, desde el punto de vista de la finalidad de la norma cuestionada, carezca de justificación objetiva y razonable, o que resulte desproporcionada en relación con dicha justificación. Lo que prohíbe el principio de igualdad son, en suma, las desigualdades que resulten artificiosas o injustificadas por no venir fundadas en criterios o juicios de valor generalmente aceptados, además de que, para que sea constitucionalmente lícita la diferencia de trato, las consecuencias jurídicas que se deriven de tal distinción deban ser proporcionadas a la finalidad perseguida, de suerte que se eviten resultados excesivamente gravosos o desmedidos (...) En cualquier caso, lo propio del juicio de igualdad es que ha de comprobarse siempre, mediante un criterio de carácter relacional que cuando se proyecta sobre la acción del legislador requiere como presupuestos obligados, de un lado, que, como consecuencia de la medida normativa cuestionada, se haya introducido directa o indirectamente una diferencia de trato entre grupos o categorías de personas(...) y, de otro, que las situaciones subjetivas que quieran traerse a la comparación sean, efectivamente, homogéneas o equiparables, es decir, que el término de comparación no resulte arbitrario o caprichoso (...) Solo una vez verificado uno y otro presupuesto resulta procedente entrar a determinar la licitud constitucional de la diferencia contenida en la norma (...)"1.

Más o menos el mismo predicamento ha adoptado el Tribunal Constitucional chileno. Conociendo de un recurso de inaplicabilidad en materia de filiación en el que se alegaba la transgresión de la igualdad ante la ley, el Tribunal señaló:

1 Sentencia del Tribunal Constitucional Español No 138, de 26 de mayo de 2005. 
"Que para efectos de dilucidar si, en el conflicto que se ha planteado, se produce una infracción al derecho a la igualdad ante la ley, es necesario determinar, en primer lugar, si realmente estamos frente a una discriminación o diferencia de trato entre personas que se encuentran en una situación similar para, luego, examinar si tal diferencia tiene el carácter de arbitraria importando una trasgresión a la Carta Fundamental. Así, debe analizarse si tal diferencia carece de un fundamento razonable que pueda justificarla y si, además, adolece de falta de idoneidad para alcanzar la finalidad que ha tenido en vista el legislador. Este criterio ha sido reiterado por esta Magistratura, entre otras, en las sentencias roles $\mathrm{N}^{\circ}$ s. 790, 825, 829 y $834 " 2$.

En suma, reproduciendo los términos de nuestra Constitución discriminación debe entenderse como establecer "diferencias arbitrarias" (artículo 19 No 2 inciso 20).

\section{IGUALDAD Y FAMILIA}

Si la aplicación del principio de igualdad debe ser siempre reflexiva y fundada en argumentos evaluativos, con mayor razón debe afirmarse esto en lo referido al Derecho de Familia. El Derecho de Familia pretende regular una comunidad de relaciones interpersonales que tienen una existencia previa o anterior a toda regulación positiva y que, además, está llamada a cumplir finalidades de bien social que son difícilmente despreciables por el sistema normativo.

Atendida su conformación natural y sus funciones sociales, la familia es un entramado de relaciones diferenciadas, que emanan de personas que ocupan y desempeñan roles diversos. Se diría que la riqueza de la familia no está en la igualdad, sino más bien en la diversidad. En el mercado, en el trabajo, los seres humanos pueden ser reducidos a la calidad de roles abstractos: consumidor, propietario, acreedor, trabajador, empleador, etc. En la familia no podría reducirse su inmensa potencialidad de diferencias y complementariedades con el rol de "familiar" o "miembro de familia". Existe una diferencia esencial entre padres e hijos, entre hermanos y primos, entre padres y tíos, tíos y sobrinos, abuelos y nietos. Incluso no es del todo exacto hablar de "padres", ya que la familia exige roles diferenciados entre los progenitores: una es la madre y otro el padre. En el matrimonio, no solo hay cónyuges, sino que hay marido y mujer. Puede coincidirse así con la provocativa afirmación del maestro romanista español Álvaro d'Ors de que la familia es una reserva natural de desigualdad.

De esta forma, una aplicación uniformadora y homogeneizante del principio de igualdad puede conducir a arrasar con la conformación propia de la familia. Por poner un ejem-

2 Sentencia del Tribunal Constitucional Chileno Rol No 1.340-09, de 29 de septiembre de 2009. 
plo, sería absurdo que se tachara de discriminatorio el trato sucesorio que reciben los sobrinos de una persona, que son excluidos como herederos abintestato por los descendientes, por el cónyuge y por los hermanos del causante.

Además, la necesidad de establecer políticas públicas que promuevan la buena constitución y la estabilidad de la familia, justifican tratos diferenciados, que, siendo proporcionados a la finalidad perseguida, pueden ser considerados necesarios para fortalecer la estructura familiar.

El mismo Derecho de Familia es un Derecho preferencial y especial que produce diferencias justificadas respecto de otras agrupaciones o convivencias entre personas que incluso puedan compartir algunos elementos propios de la familia, como la vida en común, la afectividad o la procreación.

Debe notarse que la Ley General Alemana de tratamiento igualitario: Allgemeines Gleichbehandlungsgesetz (AAG), en vigor desde agosto de 2006, y que prohíbe las conductas discriminatoria que se basen en motivos de raza, origen étnico, sexo, religión o concepción del mundo, incapacidad, edad o identidad sexual, incluso en el ámbito del derecho privado, contiene una norma que señala que esta prohibición de discriminación no es aplicable a las relaciones familiares y sucesorias $(\$ 19 \text { AGG) })^{3}$.

Con estas premisas, podemos avanzar hacia el análisis de la posible discriminación en el régimen de filiación chileno.

\section{3. ¿IGUALDAD DE LOS HIJOS O IGUALDAD DE LOS PADRES?}

Una primera cuestión que podría despejarse en cuanto a la discriminación en la filiación es cuál es el foco del análisis: si los padres o los hijos. Tenemos la impresión de que a veces se incluye como casos de discriminaciones respecto de los hijos supuestos en los que, en realidad, se trata, no de los derechos y de los intereses de los hijos, sino de los derechos e intereses de los padres sobre ellos.

Nuevamente, aquí la cuestión es si la diferencia es discriminatoria o justificada, y, lo que es más relevante, que la justificación puede provenir justamente de la necesidad de atender a una mejor protección del hijo. Lo que en el moderno Derecho de Familia se ha dado en llamar, el principio del mejor interés del niño.

Así, se puede tachar de discriminatoria la preferencia que tiene la madre para el cuidado de los hijos menores (art. 225 inc. $1^{\circ}$ Código Civil chileno -CCch-) o la que tiene el padre para la administración de los bienes del hijo que contempla nuestra legislación (art. 244

\footnotetext{
3 Cerdá Martínez-Pujalte, Carmen, "El problema de la discriminación en el ámbito privado", en Revista de Derecho Privado, Bogotá, Colombia: Universidad Externado de Colombia, No 16, 2009, pp. 119 y ss.
} 
inc. $\left.2^{\circ} \mathrm{CCch}\right)^{4}$. Pero ambas bien pueden defenderse, en que parece mejor para el interés del hijo establecer una regla fija, a falta de acuerdo de los progenitores ${ }^{5}$.

Lo mismo puede decirse respecto de la imposibilidad de que dos personas de distinto sexo no casadas o incluso del mismo sexo sean admitidas para adoptar a un niño. La ley diferencia pero a nuestro juicio con suficiente razón, y fundada en el mejor interés del niño o niño.

Otras situaciones pueden mencionarse, así como que el padre que no reconoce al hijo y que se opone a la determinación judicial, pierde los derechos patrimoniales o personales sobre dicho hijo (art. 203 CCch). También que el padre que reconoce a un hijo puede perder los efectos del reconocimiento si el hijo repudia el reconocimiento (arts. 191 y ss. CCch).

Como se ve, no puede confundirse la aplicación del principio de igualdad entre los hijos y la que debe hacerse entre los padres. Esta última está limitada no solo por la buena constitución de la familia, sino por el interés superior del hijo.

\section{DIFERENCIAS JUSTIFICADAS ENTRE LOS HIJOS}

Pero vayamos ahora a los derechos de los hijos. La ley No 19.585, de 1994, determinó que no debería seguir aplicándose la política pública de incentivo a la constitución de la familia por medio de matrimonio a través de una protección más intensa de los derechos hereditarios de los hijos matrimoniales. Con este motivo la ley igualó los derechos de los hijos de

4 En este sentido, López Rivera, Gisella, Nuevo estatuto de filiación y los derechos esenciales, Santiago, Chile: ConoSur, 2001, pp. 190, señala que la asignación a uno de los progenitores, en defecto de acuerdo o determinación judicial, de la patria potestad y del cuidado personal desconoce lo que llama "igualdad de género". También Veloso VAlEnzuela, Paulina, en SCHMIDT, Claudia y Veloso, Paulina, La filiación en el Nuevo Derecho de Familia, Santiago, Chile: ConoSur, 2001, p. 46, sostiene que la Ley No 19.585 transgredió el principio de igualdad en la relación hombre-mujer en lo referido a la patria potestad y la tuición. GÓMEZ dE LA TORRE VARGAS, Maricruz, El sistema filiativo chileno, Santiago, Chile: Edit. Jurídica de Chile, 2007, señala que la interpretación restrictiva del art. $225 \mathrm{CCch}$ es inconstitucional por transgredir la garantía de la igualdad al discriminar arbitrariamente al padre (pp. 140-141), y que lo mismo sucede con el art. 244 pero ahora por discriminación de la madre (p. 170).

5 Schmidt, Claudia, en Schmidt, Claudia y Veloso, Paulina, op. cit. (n. 4) pp. 277-278, sostiene que la atribución de la tuición de los hijos debiera ser convencional o judicial, por ser esta la "única manera de garantizar efectivamente el interés primordial de estos"; GÓMEZ DE LA TORRE VARGAS, M., op. cit. (n. 4), p. 140, señala que un sector de la doctrina ha interpretado la preferencia materna en materia de cuidado personal como una opción del legislador por el interés superior del menor por sobre el principio de igualdad, y se muestra contraria a esta interpretación: "Disiento de esta posición por cuanto se olvida que tanto el padre o la madre deben tener los mismos derechos frente al cuidado de los hijos, pensando en lo más conveniente para estos y no partiendo del supuesto de que siempre será el cuidado personal de la madre lo más conveniente". En cambio, defiende la constitucionalidad de la atribución legal, Rodríguez PINTO, María Sara, El cuidado personal de niños y adolescentes en el Nuevo Derecho de Familia, Santiago, Chile: Abeledo Perrot Legal Publishing, 2010, pp. 51 y ss. Por nuestra parte, pensamos que la opción legislativa no establece que "siempre" sea en mejor interés de los hijos el que su cuidado lo tenga la madre, sino solo cuando no haya acuerdo entre los cónyuges ni tampoco un juicio provocado por el padre para demostrar que el interés del hijo se satisface mejor con la atribución paterna de la tuición. Parece claro que es conveniente para los hijos y mucho más realista, que la ley establezca un criterio supletorio para todos los casos que no llegan a convención ni a juicio. Frente a esa necesidad parece sensato establecer que sea la madre la que tenga el cuidado personal, mientras no se demuestre que ello va en contra del interés de los menores. En el fondo, si no hay juicio es porque hay un consentimiento tácito del padre de que los hijos están mejor con la madre. 
filiación determinada respecto de sus ascendientes: matrimoniales o no matrimoniales, si bien con un incremento fuerte de los derechos sucesorios del cónyuge (que en definitiva redunda en un beneficio indirecto de los hijos concebidos en el matrimonio).

Como se ve, la igualdad se refiere a los efectos de la filiación una vez que se haya determinado, pero no a su estructura que sigue siendo diferenciada, así como con los títulos o formas de determinación y con la manera de ejercer la acciones de estado: impugnación, reclamación, desconocimiento, nulidad del reconocimiento.

Por ejemplo, la presunción de paternidad que deriva del matrimonio: pater is est quem nuptiae demostrant, la caducidad de la acción en corto plazo por parte del marido, y la exclusión de terceros de su legitimación, salvo que el marido muera. Todo ello es diferente respecto de la paternidad no matrimonial determinada por reconocimiento, donde los terceros interesados pueden impugnar.

Parece justificado que, dejando a salvo el derecho del hijo a impugnar la filiación falsa, el legislador conceda una mayor estabilidad a la filiación matrimonial del hijo ${ }^{6}$.

No nos parece, por tanto, que pueda tacharse de discriminatorio este régimen diferenciado de acciones de filiación, que tiene en cuenta la naturaleza del vínculo matrimonial y el interés del hijo de conseguir una filiación estable y cierta ${ }^{7}$.

En este sentido, resulta ilustrativa la Sentencia del Tribunal Constitucional español No 138, de 26 de mayo de 2005, que debió dirimir si el diferente régimen de impugnación de la paternidad matrimonial y extramatrimonial violaba el principio de igualdad por discri-

\footnotetext{
6 Abeliuk Manasevich, René, La filiación y sus efectos, Santiago, Chile: Editorial Jurídica de Chile, 2000, Tomo I, pp. 47-48, se pregunta por la razón que justifica la diferencia entre filiaciones si los efectos van a ser los mismos, y respecto de la presunción pater is est declara que "si este es el motivo, resulta francamente débil, porque no habría necesidad de crear toda una categoría diferente de filiación con denominación propia, solamente con una diferenciación menor en la forma de determinar la filiación. Hubiera bastado la misma disposición actual, fijando la presunción por el matrimonio como una de las formas de establecer la filiación". Pero lo que sucede es que no es solo la presunción de paternidad del marido la que justifica la diferencia entre la filiación matrimonial y no matrimonial sino su misma estructura: la matrimonial exige un doble vínculo: paterno y materno a la vez, y las formas de reclamación judicial, de desconocimiento, repudiación e impugnación. Como dice Ramos Pazos, René, Derecho de Familia. -6a edición-. Santiago, Chile: Editorial Jurídica de Chile, 2007, t. II, p. 392, "La Ley No 19.585 eliminó la distinción entre filiación legítima, natural e ilegítima. No pudo, sin embargo, prescindir de un hecho que es más fuerte que su intención de igualar a todos los hijos: que hay hijos que nacen en el matrimonio de sus padres y otros que son el fruto de relaciones extramatrimoniales. No es cierto entonces que haya igualado a todos los hijos, porque ello es contrario a la realidad". Para que desapareciera esta distinción entre filiaciones sería necesario que se aboliera el matrimonio como institución con efectos jurídicos.

7 Veloso Valenzuela, Paulina, en Schmidt, Claudia y Veloso, Paulina, op. cit. (n. 4) p. 43, incluso entendiendo que el principio de igualdad exige que se excluya toda diferencia basada en si los padres del hijo están o no casados, sostiene que cuando el Código Civil distingue entre filiación matrimonial o no matrimonial para la determinación de la filiación, "no hay aquí propiamente una vulneración del principio de igualdad" y cita el Mensaje con que el Ejecutivo envió el proyecto de ley de igualdad entre los hijos: "La única distinción que se hace en el proyecto, es la que necesariamente resulta de la determinación de la filiación, ya que para el establecimiento de esta no puede ignorarse que el matrimonio otorga un principio de certeza, que permite presumir la paternidad del marido. Este hecho ha de influir -como es fácil observar- en el régimen jurídico a que se sometan las acciones de reclamación de una filiación matrimonial, el que, por cierto, habrá de diferenciarse de aquel establecido para el caso de que se reclame una filiación extramatrimonial (...)”.
} 
minación arbitraria. El Tribunal desechó la inconstitucional por entender que el legislador puede establecer diferencias justificadas en la filiación. Después de asentar que el principio no excluye cualquier diferencia sino solo aquellas que sean injustificadas, señala que el juicio de igualdad, en virtud del art. 14 de la Constitución española, exige la identidad de los supuestos fácticos que se pretenden comparar, pues lo que se deriva del citado precepto es el derecho a que supuestos de hecho sustancialmente iguales sean tratados idénticamente en sus consecuencias jurídicas:

"Por ello toda alegación del derecho fundamental a la igualdad precisa para su verificación un tertium comparationis frente al que la desigualdad se produzca, elemento de contraste que ha de consistir en 'una situación jurídica concreta en la que se encuentren otros ciudadanos u otros grupos de ciudadanos' (ATC 209/1985, de 20 de marzo, FJ 2). Conviene por todo ello examinar si los supuestos de hecho aportados por el órgano judicial como término de comparación guardan la identidad que todo juicio de igualdad requiere (...). Pues bien, en el presente caso, los términos de comparación ofrecidos por el órgano judicial proponente de la cuestión no ofrecen la homogeneidad necesaria para poder trabar con seguridad un juicio de igualdad en la ley. En efecto, mientras que el art. 136 CC se refiere a la impugnación de la paternidad matrimonial establecida en virtud de presunción legal, los arts. 138 y 141 del propio Código se refieren a la impugnación por vicio del consentimiento de la filiación matrimonial y no matrimonial determinadas por reconocimiento. -Los supuestos de hecho contemplados no presentan una igualdad sustancial y la diferenciación normativa establecida está dotada de una justificación suficiente, objetiva y razonable. Tal justificación radica en última instancia en los distintos regímenes de determinación de la filiación, y más concretamente de la paternidad. En efecto, es el hecho de la existencia del matrimonio el que fija el carácter matrimonial de la filiación, determinándose legalmente la paternidad del marido de la madre a través del juego de las presunciones (arts. 116 y 117 CC), basadas en la regla proveniente del Digesto pater vero is est quem nuptiae demonstrant, cuando el nacimiento se ha producido ex uxore, conectada con los deberes de convivencia y fidelidad de los cónyuges (art. 68 CC) y la presunción de convivencia conyugal (art. 69 CC). En razón del juego de presunciones establecidas por el legislador, es el nacimiento del hijo después de la celebración del matrimonio y antes de los trescientos días siguientes a la disolución del mismo o a la separación efectiva, sea legal o de hecho, de los cónyuges lo que determina la paternidad matrimonial, la cual se acredita, entre otros medios (arts. 113 y 115 CC), por la inscripción del nacimiento en el Registro Civil, que resulta ser así un título de legitimación privilegiado del estado civil de hijo matrimonial. Ahora bien, la filiación paterna puede también tener lugar 
mediante reconocimiento en los casos legalmente establecidos, tanto para la filiación matrimonial (arts. 118 y 119 CC), como para la filiación no matrimonial (arts. 120.1 y 121 a 126 CC). Este reconocimiento de la paternidad es un acto personalísimo puro (esto es, no sujeto a condición, término o modo) mediante el que declara que ha existido el hecho biológico de la procreación del que ha nacido el hijo sobre el que recae el reconocimiento. En consecuencia, al determinarse en estos casos la filiación por un acto de consentimiento, es necesario para su validez que este no se encuentre afectado por alguno de los vicios que invalidan el mismo (error, violencia o intimidación). No puede por ello extrañar que el legislador haya establecido que, en caso de concurrir alguno de esos vicios invalidantes del consentimiento, el plazo de un año para ejercitar la acción de impugnación de la paternidad declarada por reconocimiento comience a computarse desde que el vicio ha cesado (arts. 138 y 141 CC)-. En definitiva, la acción de impugnación de la paternidad matrimonial del art. 136 CC descansa sobre presupuestos diferentes que las acciones de impugnación contempladas en los arts. 138 y $141 \mathrm{CC}$, lo que justifica que el legislador haya establecido un diferente dies a quo para el cómputo del plazo de la acción de impugnación de la paternidad en atención a las distintas formas de determinación de la filiación, sin que tal diferenciación normativa pueda reputarse como arbitraria, discriminatoria o carente de fundamento conforme a lo expuesto" 8 .

Creemos acertada la solución que da el Tribunal español a la cuestión de constitucionalidad, y las mismas razones podrían esgrimirse para justificar las diferencias que se presentan análogamente en el régimen legal chileno de filiación entre acciones para impugnar y reclamar las filiaciones matrimoniales y no matrimoniales.

\section{POSIBLES CASOS DE DISCRIMINACIÓN ENTRE LOS HIJOS}

\subsection{RECLAMACIÓN POSTMORTEM DE LA PATERNIDAD}

Un caso que ha sido recientemente debatido en nuestros tribunales en el que se alegó la violación del principio de igualdad es el de la reclamación de la paternidad cuando el supuesto padre ha ya fallecido. El art. 206 del Código Civil, avalado por la historia del establecimiento de la ley, limitó la acción de reclamación de la paternidad en caso de fallecimiento del progenitor. Solo exceptuó los casos en los que el padre fallece antes del nacimiento del hijo (hijo póstumo) o en el breve plazo de 180 días contados desde el parto: "Si el hijo es

8 Sentencia del Tribunal Constitucional español No 138, de 26 de mayo de 2005. 
póstumo -dice la norma-, o si alguno de los padres fallece dentro de los ciento ochenta días siguientes al parto, la acción podrá dirigirse en contra de los herederos del padre o de la madre fallecidos (...)".

El Tribunal Constitucional chileno declaró inaplicable por inconstitucionalidad este artículo, por entender que al limitarse el derecho a investigar la paternidad del presunto padre ya fallecido se vulneraba el derecho a la identidad. Pero consideró también que existía una violación de la igualdad ante la ley, que no podía ser razonablemente justificada, tomando para ello los antecedentes de la historia del establecimiento del precepto durante la discusión de la ley No 19.585:

"Que en lo atingente al criterio que nos ocupa, el examen de la historia del establecimiento del artículo 206 del Código Civil revela que, lejos de apreciarse un fundamento objetivo y razonable en la limitación que dicha norma establece para reclamar de los herederos del padre o madre fallecidos el reconocimiento de la filiación, se tuvo en cuenta la regulación contenida en una norma precedente que aludía a una distinción entre tipos o categorías de hijos que el proyecto del Ejecutivo quiso precisamente superar. Por lo tanto, se consideró un criterio que ya no tenía cabida en la nueva legislación y que motivó -como se ha recordado- críticas de parte de algunos parlamentarios, precisamente por estimarse que introducía una diferencia entre aquellos cuyo padre o madre fallece antes o después de los 180 días siguientes al parto, generando, por ende, un vacío legal"9.

No estamos de acuerdo con esta parte de la sentencia del Tribunal ya que nos parece que deben distinguirse dos situaciones: primero, si se justifica que la acción de reclamación de la paternidad se extinga por la muerte del supuesto padre y si esto hiere la igualdad ante la ley, ya que se diferenciará entre hijos cuyo padre no ha fallecido y que pueden demandar la paternidad y otros que carecerán de la acción por el fallecimiento del progenitor. Esta di-

9 Sentencia del Tribunal Constitucional, considerando $34^{\circ}$. Rol No 1.340-09, 29 de septiembre de 2009. En el considerando conclusivo la sentencia parece confundir el supuesto del plazo de 180 días que no es para conocer la muerte del padre sino para que el hijo nazca: "la diferencia de trato introducida por el artículo 206 del Código Civil importa que si, como en la especie, una persona se entera de su verdadera filiación después de transcurridos 180 días de la muerte de su padre, frente a quien lo hace antes de transcurrido ese término, y como consecuencia de ello, se ve privada de poder accionar en pos del reconocimiento de la paternidad respectiva, ve afectado su derecho a la igualdad ante la ley" (cons. 36). VELOSO VALENZUELA, Paulina, en SCHMIDT, Claudia y Veloso, Paulina, op. cit. (n. 4) p. 133, había señalado que la imprescriptibilidad de la acción de reclamación no se oponía a la extinción de ella en caso de muerte, salvo ciertos casos limitados, pero haciendo presente que la validez de este tipo de delimitación enfrente al derecho de identidad ha sido un asunto discutido en el derecho comparado. La misma autora reproduce los considerandos de la sentencia de la Corte Suprema de Costa Rica, de 12 de marzo de 1999 (No 1894-99) por la cual se declaró inconstitucional la norma del Código de Familia de dicho país que establecía un plazo de caducidad de un año después de la muerte para reclamar la filiación en contra de los herederos del presunto progenitor. Esta sentencia es también mencionada por el Tribunal Constitucional chileno (cons. $17^{\circ}$ ). 
ferencia nos parece justificada porque es diferente, incluso para la defensa en el pleito, que el posible padre haya muerto o no. Si ha muerto, están también en juego los derechos a la intimidad familiar de los herederos, la integridad psíquica de los familiares que verán exhumados los restos de su causante, la estabilidad de las sucesiones. Además, permitir la acción post mortem podría constituir un incentivo perverso que tienda a que no se reconozcan los hijos en vida y a que no se demande la reclamación, esperando el fallecimiento del supuesto progenitor. El derecho a la identidad podría quedar resguardado si se estimara que los procesos iniciados después de la muerte del padre no producen efectos sucesorios.

Si se esclarece que la extinción de la acción por muerte del supuesto padre o madre no atenta contra la igualdad ante la ley, es necesario entrar a una segunda cuestión, que es si la excepción: hijo póstumo o nacido en los 180 días siguientes a la muerte del padre, constituye una diferencia arbitraria o no, en cuanto a que los hijos que se encuentran en esta situación podrían demandar la reclamación y los que quedan fuera de ella no podrían hacerlo. La justificación que da la sentencia para afirmar la inconstitucionalidad en el sentido de que con ello se intentaba reproducir una norma del antiguo régimen legal que diferenciaba entre los hijos, es errónea. La excepción se motivó en que parecía conveniente cambiar la extinción de la acción por un plazo de caducidad cuando la temprana muerte del padre podía impedir o dificultar fuertemente el ejercicio de la acción de reclamación por parte del hijo (aun no nacido o recién nacido) o del representante legal. La justificación de la excepción parece sensata y sustentable, si bien los plazos (por ejemplo, el de 180 días) son inevitablemente discrecionales.

Pero lo que no parece correcto es evaluar negativamente la excepción argumentando en contra de la regla general. Aquí hay una falencia discursiva importante de la sentencia de nuestro Tribunal Constitucional en materia de igualdad ante la ley y régimen de filiación ${ }^{10}$.

\subsection{INVESTIGACIÓN DE LA PATERNIDAD EN LAS TÉCNICAS DE REPRODUCCIÓN ASISTIDA}

Otro caso que puede considerarse en relación con el cumplimiento de la garantía de igualdad en la filiación es el que proviene de la diferencia de trato entre el hijo concebido mediante cópula sexual y el hijo concebido mediante la aplicación de técnicas de reproducción asistida con aportación de gametos de terceros.

El art. 182 del Código Civil, al tratar del hijo concebido mediante técnicas de reproducción asistida señala que su padre y su madre son el hombre y la mujer que se sometieron a esas técnicas, con lo cual descarta la determinación filiativa del tercero aportante de gametos.

\footnotetext{
10 Sobre el problema de interpretación que ha suscitado el art. 206, en relación con el art. 317 del Código Civil, puede verse nuestro trabajo: CORRAL TALCIANI, Hernán, “¿Puede interponerse la acción de reclamación de filiación en contra de los herederos del supuesto padre fallecido?”, en: Gaceta Jurídica No 347, Santiago, Chile: 2009, pp. 7-22.
} 
Se dice igualmente que la filiación así determinada no puede ser objeto de impugnación ni reclamarse otra distinta.

Si se interpreta que esta norma también rige para el hijo, se ha puesto una lápida al derecho a conocer la identidad al menos del progenitor biológico ${ }^{11}$. Aquí sí que parece haber una diferencia que encuentra justificación. No se entiende cuál es la razón que fundamenta este menoscabo del derecho a investigar la paternidad o maternidad por el solo hecho, en cuya decisión él no ha participado, de haber sido producto de una técnica reproductiva con uso de gametos de terceros ${ }^{12}$.

Si los padres en vez de recurrir a las técnicas de reproducción asistida hubieran recurrido a un adulterio consentido, nadie dudaría de que el hijo puede impugnar la filiación del marido y reclamar la del tercero que inseminó a la mujer.

Es más, si se aplica el esquema de la adopción, se ve que nuestra ley, dejando a salvo el vínculo filiativo de la adopción, concede derecho al adoptado mayor de edad a acceder al conocimiento de su verdadera identidad por medio de la consulta de los antecedentes de la adopción (v. artículo 27 ley No 19.620). Algo parecido podría, al menos, garantizarse al hijo concebido por medio de técnicas reproductivas heterólogas, para los cual los centros médicos que las practican debieran mantener registros rigurosos y permanentes, a fin de que puedan ser consultados por los posibles interesados ${ }^{13}$.

11 Por nuestra parte, hemos intentado efectuar una interpretación que deja a salvo la acción de reclamación del hijo: cfr. CORRAL TALCIANI, Hernán, "Reproducción humana asistida y filiación: un análisis del nuevo artículo 182 del Código Civil", en Primeras Jornadas de Derecho Médico, Cuadernos Jurídicos 2. Santiago, Chile: Universidad Central, 2000, pp. 169-177. En contra se pronuncia ABELIUK MANASEVICH, René, op. cit. (n. 6) t. I, p. 121, por estimar que el sentido de la disposición es claro en cuanto a incluir al hijo en la prohibición de impugnar y reclamar, si bien parece discrepar de la justicia de la disposición en este aspecto: "Que la solución puede ser criticable no cabe duda, pero ello no puede permitir torcer su claro sentido".

12 Abeliuk ManaseVich, René, op. cit. (n. 6) t. I, p. 121, se plantea el problema de si la norma puede ser considerada inconstitucional o contraria a las convenciones internacionales suscritas por Chile y declara que "no puede considerarse sin más ni más que la esta norma infringe tales disposiciones, máxime si, como puede apreciarse, hay división al respecto incluso en el extranjero". Pero el hecho de que haya dudas en las legislaciones sobre si debe protegerse el anonimato del donante o el derecho del hijo a conocer la identidad de sus progenitores no puede, por sí mismo, constituir un argumento para sostener la justicia de la discriminación entre hijos por el hecho de su nacimiento.

13 Sin pronunciarse sobre la posible inconstitucionalidad de la norma del art. 182 del Código Civil, GÓMEZ DE LA TORRE VARGAS, Maricruz, op. cit. (n. 4) p. 126, declara: "considero que el hijo que nace producto de la aplicación de una TRA [Técnica de Reproducción Asistida] con donante debe tener la posibilidad de saber que fue concebido por este procedimiento y quién es su progenitor biológico, cuando alcance la mayoría de edad, estableciendo un sistema similar a la Ley de Adopción, que permite al adoptado cuando llega a la mayoría de edad saber quién es su progenitor biológico". 


\section{REFERENCIAS BIBLIOGRÁFICAS}

Abeliuk Manasevich, René. La filiación y sus efectos, Santiago, Chile: Editorial Jurídica de Chile, 2000.

Cerdá MARTínez-Pujalte, Carmen, "El problema de la discriminación en el ámbito privado", en Revista de Derecho Privado. Bogotá, Colombia: Universidad Externado de Colombia, No 16, 2009.

CORRAL TALCIANI, Hernán, “¿Puede interponerse la acción de reclamación de filiación en contra de los herederos del supuesto padre fallecido?”, en: Gaceta Jurídica No 347, 2009.

CORRAl TAlCiAni, Hernán. "Reproducción humana asistida y filiación: un análisis del nuevo artículo 182 del Código Civil", en Primeras Jornadas de Derecho Médico, Cuadernos Jurídicos 2. Santiago, Chile: Universidad Central, 2000.

Gómez de la Torre VArgas, Maricruz. El sistema filiativo chileno. Santiago, Chile: Editorial Jurídica de Chile, 2007.

López Rivera, Gisella. Nuevo estatuto de filiación y los derechos esenciales, Santiago, Chile: ConoSur, 2001.

Ramos Pazos, René. Derecho de Familia. -6a Edición-Santiago, Chile: Editorial Jurídica de Chile, 2007.

Rodríguez PinTo, María Sara. El cuidado personal de niños y adolescentes en el Nuevo Derecho de Familia, Santiago, Chile: Abeledo Perrot Legal Publishing, 2010.

Schmidt, Claudia y Veloso, Paulina. La filiación en el Nuevo Derecho de Familia, Santiago, Chile: ConoSur, 2001. 